\title{
The Growth of Learning
}

T The renaissance in mathematical learning during the Middle Ages was largely due to three factors: the translation of Arabic classical texts into Latin during the 12th and 13th centuries, the establishment of the earliest European universities, and the invention of printing. The first of these made the works of Euclid, Archimedes, and other Greek writers available to European scholars, the second enabled groups of like-minded scholars to meet and discourse on matters of common interest, whereas the last enabled scholarly works to be available at modest cost to the general populace.

The first European university was founded in Bologna in 1088, and Paris and Oxford followed shortly after. The curriculum was in two parts. The first of these, studied by those aspiring to a Bachelor's degree, was based on the ancient "trivium" of grammar, rhetoric, and logic (usually Aristotelian). The second part, leading to a Master's degree, was based on the "quadrivium," the Greek mathematical arts of arithmetic, geometry, astronomy, and music; the works studied would have included Euclid's Elements and Ptolemy's Almagest.

Johann Gutenberg's invention of the printing press around 1440 enabled classic mathematical works to be widely available for the first time. At first the new books were printed in Latin for the scholar, but increasingly vernacular works appeared at prices accessible to all; these included texts in arithmetic, algebra, and geometry, as well as practical works designed to prepare young men for a commercial career.

Important among the new printed texts was the 1494 Summa de Arithmetica, Geometrica, Proportioni et Proportionalita of Luca Pacioli (1445-1517), a 600-page compilation of the mathematics known at the time; it included the first published account of double-entry bookkeeping. In Germany the most influential of the commercial arithmetics was by Adam Riese (c.1489-1559); it proved so reputable that the phrase "nach Adam Riese" [after Adam Riese] came to refer to a correct calculation.

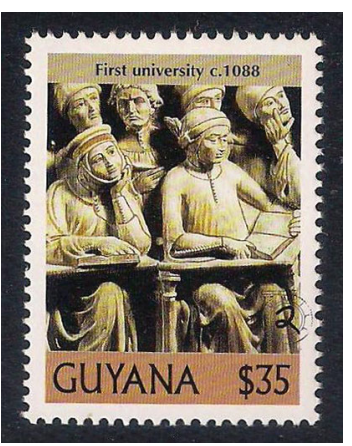

University of Bologna

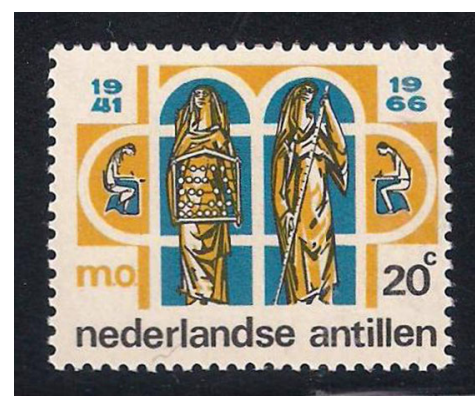

Arithmetic and geometry

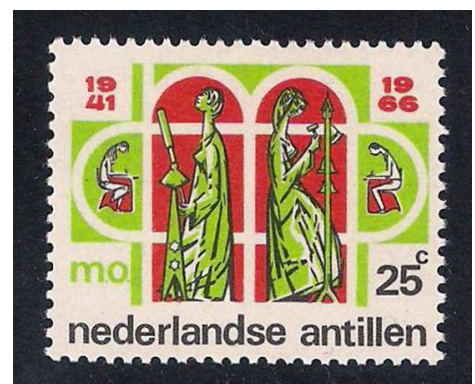

Astronomy and music

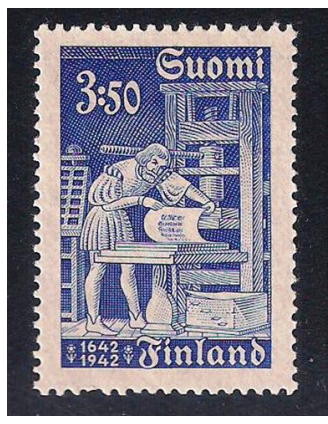

Printing press

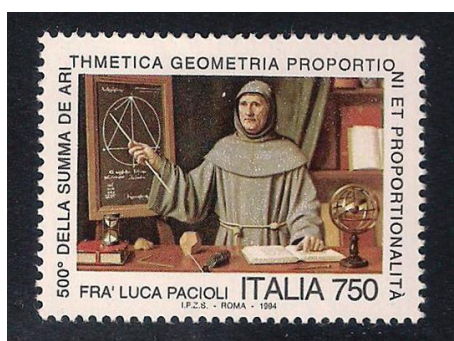

Luca Pacioli

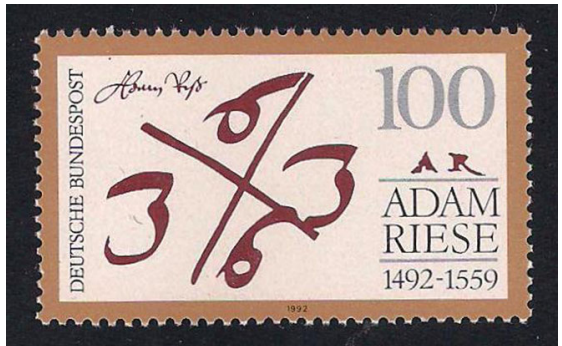

Adam Riese

> Column editor's address: Robin Wilson, Pembroke College,

Oxford, OXI IDW, UK

e-mail: r.j.wilson@open.ac.uk 